\title{
Aerosol Properties over Southeastern China from Multi-WaVelength RAMAN AND DEPOlaRization Lidar MEASUREMENTS
}

\author{
Birgit Heese $^{1 *}$, Dietrich Althausen ${ }^{1}$, Holger Baars ${ }^{1}$, Stephanie Bohlmann', Ruru Deng ${ }^{2}$ \\ ${ }^{1}$ Leibniz Institute for Tropospheric Research (TROPOS), Permoserstr. 15, 04318 Leipzig, Germany, \\ *Email: heese@tropos.de \\ ${ }^{2}$ School of Geography and Planning, Sun Yat-sen University, Guangzhou, China
}

\begin{abstract}
A dataset of particle optical properties of highly polluted urban aerosol over the Pearl River Delta, Guangzhou, China is presented. The data were derived from multi-wavelengths Raman and depolarization lidar Polly ${ }^{\mathrm{XT}}$ and AERONET sun photometer measurements. The measurement campaign was conducted from Nov 2011 to June 2012. High aerosol optical depth was observed in the polluted atmosphere over this megacity, with a mean value of $0.54 \pm 0.33$ and a peak value of even 1.9. For the particle characterization the lidar ratio and the linear particle depolarization ratio, both at $532 \mathrm{~nm}$, were used. The mean values of these properties are $48.0 \mathrm{sr} \pm 10.7 \mathrm{sr}$ for the lidar ratio and $4 \%+-4 \%$ for the particle depolarization ratio, which means most depolarization measurements stayed below $10 \%$. So far, most of these results indicate urban pollution particles mixed with particles arisen from biomass and industrial burning.
\end{abstract}

\section{INTRODUCTION}

The Southeast of China, i.e. the Pearl River Delta (PRD) is one of the largest urbanized areas in the world. High population density and a very strong economy leads to high aerosol load in the whole area around Guangzhou (PRD). The consequences for the geographical development, people's health, and atmospheric pollution were studied in the frame of the German project "Megacities Megachallenges". The atmosphere over the PRD is influenced by high urban and industrial activity but is also affected by the vicinity of the sea. Hence the predominant atmospheric particles expected in this area may be a mixture of different aerosol types like urban haze, pollution, dust, and sea-salt particles.
The atmospheric conditions of the PRD are controlled by subtropical to tropical climate with an annual average temperature of about $22{ }^{\circ} \mathrm{C}$. The weather is influenced by the Asian monsoon circulation. The main wind direction turns with the change of the location of the Inter Tropical Convergence Zone from north and north-easterly wind directions during the winter months to southern directions during the summer months.

Several studies concerning the vertical aerosol structure in PRD have been performed. First lidar measurements in the PRD by TROPOS were carried out during a one-month intensive field campaign in Xinken in 2004. The first prototype of the mobile single-wavelengths Raman lidar Polly with two detection channels was used. The observed aerosol was mainly dominated by local pollution [1].

As part of the Megacities project, a first short field campaign took place in November and December 2009. During this time, two events of moderate and hazy pollution were observed by the Raman lidar of the Anhui Institute of Optics and Fine Mechanics, CAS, Hefei, China Hefei Optics Institute and a sun photometer from TROPOS [2].

For the investigation of the different seasonal aerosol conditions a longer lasting field campaign was necessary. For this reason, a second field campaign was performed in the PRD in 2011/12. At that time, the multi-wavelength Raman lidar Polly ${ }^{\mathrm{XT}}$ [3] with depolarization capabilities was used for the characterization of the aerosol types over the PRD. In the next chapter the deployed instruments and their products are described. The results are presented in chapter 3 and the conclusions given in chapter 4 . 


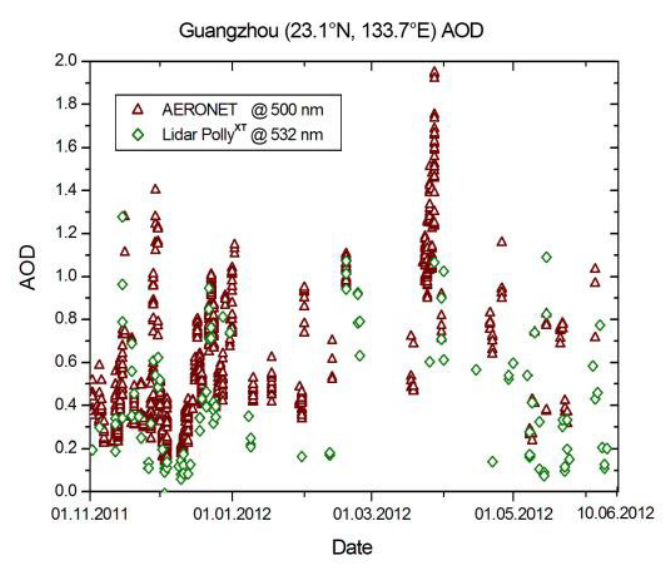

Figure 1: AOD derived from Polly ${ }^{\mathrm{XT}}$ Raman extinction measurements at $532 \mathrm{~nm}$ and AERONET level 2 AOD derived from sun photometer measurements at $500 \mathrm{~nm}$. Lidar particle extinction profiles were extrapolated as shown in Fig 2.

\section{METHODOLOGY}

Together with the multi-wavelength Raman lidar Polly ${ }^{\mathrm{XT}}$ of TROPOS a dual-polar sun photometer of type CE-318dp was deployed on the roof top of a building on the East-Campus of the Sun Yat-sen University of Guangzhou. The measurements started in the end of October 2011 and lasted until the beginning of July 2012. The optical properties measured by the lidar are the particle backscatter coefficient at $355 \mathrm{~nm}, 532 \mathrm{~nm}$ and $1064 \mathrm{~nm}$, the particle extinction coefficient at $355 \mathrm{~nm}$ and 532 $\mathrm{nm}$, and the linear depolarization ratio at $532 \mathrm{~nm}$. For the deter-mination of the particle backscatter coefficient and particle extinction coefficient the Raman method has been applied. Further derived optical properties are the particle extinction-tobackscatter-coefficient ratio or lidar ratio, the linear particle depolarization ratio, the AOD, and the respective backscatter and extinction related Ångström exponents.

The sun-photometer measures the direct and indirect sun radiation at eight wavelength from $340 \mathrm{~nm}$ up to $1640 \mathrm{~nm}$. In addition, with this dualpolar instrument, the radiances at three different depolarization directions are measured by means of a second filter wheel. The data presented here are mainly the AOD derived from the direct sun measurements.

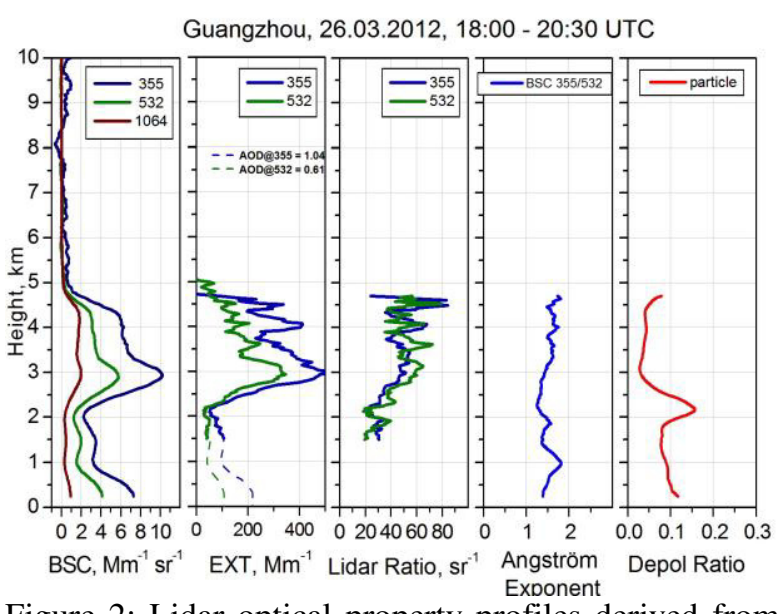

Figure 2: Lidar optical property profiles derived from Polly ${ }^{\mathrm{XT}}$ measurement on March 26, 2012 (local time is $+8 \mathrm{~h}, 02: 00$ to $04: 30 \mathrm{LT})$ ). Vertical smoothing was $450 \mathrm{~m}$ for the profiles shown here.

\section{RESULTS}

An overview over the typical aerosol conditions during the observation period is given by the aerosol optical depth (AOD). Fig. 1 shows AERONET level 2 AOD values at $500 \mathrm{~nm}$ measured by the sun photometer and the AOD values derived from Polly ${ }^{\mathrm{XT}}$ Raman extinction profiles. During November and December 2011, sun photometer AOD values are available on 17 and 22 days, respectively. After this period, a lot of rain and cloudy weather was present over Guangzhou. Thus, in 2012, level 2 sun photometer data are only available on 32 days in total. However, these data still provide an overview over the development of the aerosol load throughout the observation period. In the beginning, in November and December 2011, most AOD values range between 0.2 and 0.6 with some peak AOD periods with high values up to 1.4 .

The monthly mean AOD are still moderate with values of $\mathrm{AOD}=0.45 / 0.46 \quad(\mathrm{SPM} / \mathrm{Lidar})$ in November and $A O D=0.49 / 0.33$ in December. In January $(\mathrm{AOD}=0.57 / 0.24)$ and in February $(\mathrm{AOD}=0.93 / 0.68)$ the mean values are larger but only a few observations were available. Unusual heavy rainfall was observed which may be triggered by a La Niña event during that winter. In March, a period with very high AOD values was observed. The maximum value of 1.95 was 
measured on March 28, 2012, so that the highest monthly mean AOD of 1.16 was reached.

Towards the summer season, the mean AOD decreases to 0.82/0.81 in April and 0.49/0.35 in May. In the beginning of June the mean AOD value was $0.32 / 0.37$. For the whole observation period, the mean AOD value was $0.54 \pm 0.33$, which indicates a generally high mean background level of aerosol in the atmosphere above the PRD. For comparison, in Leipzig, Germany, a continental, central European site, the yearly mean AOD at $500 \mathrm{~nm}$ lies around 0.2.

The mean AOD for the whole observation period derived from the lidar measurements is $0.43 \pm 0.30$. These AOD values were calculated by integrating the particle extinction profiles from the uppermost level of the observed aerosol layers to the overlap height. The overlap height mostly lies around $1 \mathrm{~km}$. Below this height, the remaining profile was extrapolated by fitting the particle backscatter profiles to the particle extinction profile. This is illustrated in the second graph of Fig. 2. Finally, the last few hundred meters to the ground were extrapolated using the lowermost profile value. This procedure obviously underestimates the AOD by about $12 \%$, so that the lidar AOD values often are below the AERONET values, as can be seen in Figure 1.

Although the AOD measurements by the sun photometer already show seasonal differences in the aerosol, these measurements are still column integrated. Thus, a detailed analysis was performed using the vertical information obtained by the lidar measurements.

One example of the obtained lidar profiles is presented in Fig. 2. It shows the profiles of the particle backscatter coefficient, the particle extinction coefficient, and the resulting lidar ratio, the backscatter related Ångström exponent, and the linear particle depolarization ratio from a measurements on March 26, 2012 from 18:00 to 20:30 UTC. Here, a lofted layer at altitude ranges between 2 and $5 \mathrm{~km}$ with particle properties that differ from those in the planetary boundary layer (PBL) was observed. This is an example with very high aerosol content. The AOD on this day was among the highest values during the observation period: 1.04 at $355 \mathrm{~nm}$ and 0.61 at $532 \mathrm{~nm}$. However, this type of particle layer structure was

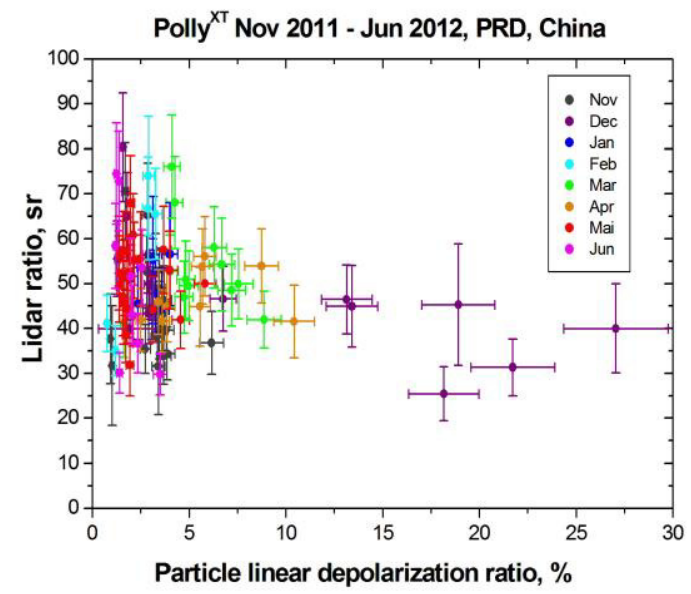

Figure 3: Lidar ratio versus linear particle depolarization ratio $532 \mathrm{~nm}$ for elevated layers period November 2011 to June 2012.

observed often above the measurements site. The upper boundary of these upper layers lies between $2.5 \mathrm{~km}$ and up to even $5 \mathrm{~km}$, as in this example. In most cases, the PBL was observed below $1.5 \mathrm{~km}$, as on this day. Since no overlap correction could be performed, the PBL is not captured by the Raman particle extinction profiles.

Therefore, the PBL is not included in the following discussion and the focus is laid on the lofted layers.

For all observed lofted layers above $1.5 \mathrm{~km}$ the lidar ratio has been calculated and has been plotted against the linear particle depolarization ratio for $532 \mathrm{~nm}$ (Fig. 3). For each data point the lidar measurements were integrated over at least 2 hours and vertically smoothed over a window of $750 \mathrm{~m}$. Each month has been coded by a color for easier identification. The lidar ratio is derived from Raman retrievals of the particle backscatter and extinction coefficient profiles. The linear depolarization ratio was calculated using the 90degree calibration method described in detail in [4]. Fig. 3 shows that most data points range between a lidar ratio of $30 \mathrm{sr}$ and $80 \mathrm{sr}$. The linear depolarization ratio lies in $90 \%$ of all cases below $10 \%$ and $80 \%$ even below $5 \%$. Only a few cases of high linear depolarization ratio $>20 \%$ were observed. This was on December 2 and 3, 2011 during the only dust advection event [5]. The monthly mean values for the lidar ratios range from $43.9 \mathrm{sr}$ to $53.2 \mathrm{sr}$ with standard deviations of 5 to $10 \mathrm{sr}$ and even $16.7 \mathrm{sr}$ in one case. The 
monthly mean linear depolarization ratio ranges from $1.9 \%$ to $8.7 \%$. The mean lidar ratio value for the whole observation period is $48.0 \pm 10.7 \mathrm{sr}$. Here, the standard deviation represents the atmospheric variability. These lidar ratios indicate a wide variety of particles that were observed. The total mean value linear particle depolarization ratio is $4 \% \pm 4 \%$, indicating mainly particles with low depolarization properties such as urban pollution particles arising from traffic and fuel and other burning processes.

\section{CONCLUSIONS}

A data set obtained by a multi-wavelengths Raman and depolarization lidar and dual-polar sun photometer taken in Guangzhou, PRD, China, has been presented. In this study, the upper layers that were frequently observed have been studied. The derived particle optical properties AOD, lidar ratio, and linear particle depolarization ratio allows the conclusion, that mostly urban, industrial, and possibly biomass burning pollution is frequently present in the atmosphere over the PRD. Further analysis will be done to investigate different advection regimes and particle properties inside the lower PBL.

\section{ACKNOWLEDGEMENT}

The measurements were conducted in the frame of the special priority program "MegacitiesMegachallenge - Informal Dynamics of Global Change" (SPP 1233) funded by the German Research Foundation (DFG).

We thank our colleagues from the Sun Yat-sen University, Guangzhou, for their support and help throughout the measurement campaign.

\section{REFERENCES}

[1] Ansmann A., R. Engelmann, D. Althausen, U. Wandinger, M. Hu, Y. Zhang, and Q. He, 2005: High aerosol load over the Pearl River Delta, China, observed with Raman lidar and Sun photometer, Geophys. Res. Lett. 32, L13815, doi:10.1029/2005GL023094.

[2] Chen, Z., W. Liu, B. Heese, D. Althausen, H. Baars, T. Cheng, X. Shu, and T. Zhang, 2014, Aerosol optical properties observed by combined Raman-elastic backscatter lidar in winter 2009 in Pearl River Delta, south China, J. Geophys. Res. 119, 2496-2510, doi:10.1002/2013JD020200.

[3] Althausen, D., R. Engelmann, H. Baars, B. Heese, A. Ansmann, D. Müller, M. Komppula, 2009: Portable Raman Lidar Polly ${ }^{\mathrm{XT}}$ for Automated Profiling of Aerosol Backscatter, Extinction, and Depolarization. J. Atmos. Oceanic Technol., 47, pp. 2366-2378.

[4] Freudenthaler, V., Esselborn, M., Wiegner, M., Heese, B., Tesche, M., Ansmann, A., Müller, D., Althausen, D., Wirth, M., Fix, A., Ehret, G., Knippertz, P., Toledano, C., Gasteiger, J., Garhammer, M., Seefeldner, M. 2009: Depolarization ratio profiling at several wavelengths in pure Saharan dust during SAMUM 2006. Tellus, 61B, 165-179.

[5] Heese B., Althausen, D., Bauditz, M., Bao, R., Deng, R., Li, Z., 2012, Lidar depolarization and sun photometer polarization measurements for particle characterization over Guangzhou, China, Proceedings of the 26th ILRC, Porto Heli, Greece, 25-29 June, 505-509. 